\title{
Effect of polymer concentration and length of hydrophobic end block on the unimer-micelle transition broadness in amphiphilic ABA symmetric triblock copolymer solutions
}

\author{
X.-G. Han ${ }^{112 *} ;$ Y.-H. Ma $2^{112}$, S.-L. Ouyang ${ }^{2}$ \\ 1 School of Mathematics, Physics and Biological engineering, Inmongolia Science and Technology University, \\ Baotou 014010, China \\ 2 Key laboratory of Integrated Exploitation of Bayan Obo Multi-Metal Resources, Inmongolia Science and \\ Technology University, Baotou 014010, China
}

Received December 7, 2012, in final form March 28, 2013

\begin{abstract}
The effects of the length of each hydrophobic end block $N_{\text {st }}$ and polymer concentration $\bar{\phi}_{\mathrm{P}}$ on the transition broadness in amphiphilic ABA symmetric triblock copolymer solutions are studied using the self-consistent field lattice model. When the system is cooled, micelles are observed, i.e.,the homogenous solution (unimer)micelle transition occurs. When $N_{\text {st }}$ is increased, at fixed $\bar{\phi}_{\mathrm{P}}$, micelles occur at higher temperature, and the temperature-dependent range of micellar aggregation and half-width of specific heat peak for unimer-micelle transition increase monotonously. Compared with associative polymers, it is found that the magnitude of the transition broadness is determined by the ratio of hydrophobic to hydrophilic blocks, instead of chain length. When $\bar{\phi}_{\mathrm{P}}$ is decreased, given a large $N_{\mathrm{St}}$, the temperature-dependent range of micellar aggregation and halfwidth of specific heat peak initially decease, and then remain nearly constant. It is shown that the transition broadness is concerned with the changes of the relative magnitudes of the eductions of nonstickers and solvents from micellar cores.
\end{abstract}

Key words: transition broadness, self-consistent field, amphiphilic copolymer

PACS: $61.25 . \mathrm{Hp}, 64.75 .+\mathrm{g}, 82.60 . \mathrm{Fa}$

\section{Introduction}

Amphiphilic block copolymers are particularly versatile macromolecules because they allow for a rich variety of different structures. Their length and the number of blocks of each species can be tuned at will, from di- and triblock to multiblock copolymers. Their architectures can be linear, branched or starlike, the blocks may be distributed randomly or regularly. Consequently, amphiphilic block copolymers have a great deal of applications such as drug delivery vectors [1], nanoparticle stabilizers, nanoreservoirs, emulsion stabilizers, wetting agents, rheology modifiers [2, 3] or as injectable scaffold materials for tissue engineering [4].

Amphiphilic copolymers are capable of self-assembling into micelles when temperature drops to a critical micelle temperature. Below the critical micelle temperature there is an equilibrium region of a certain width, where significant amounts of both free and associated copolymer molecules coexist. Above the transition region most copolymer molecules are in micelles. It is verified theoretically [5] and experimentally [6] that the broad nature should be ascribed to the structural changes which accompany the replacement of micellar core solvent by polymer. However, the effect of the hydrophobic block on the structural changes is not clarified so far, which is very important in high polymer concentration

\footnotetext{
*E-mail: xghan0@163.com, Phone: 011+086-472-5954303, Fax: 011+086-472-5954303
} 
regimes. The study of the effects of polymer concentration and length of hydrophobic end block on the transition broadness in amphiphilic ABA symmetric triblock copolymer solutions would be quite useful to understand the thermodynamics of block copolymers in a selective solvent.

The self-consistent field theory (SCFT) has been brought into use as a powerful tool in predicting the morphologies of complex block copolymers [7-10]. Recently, SCFT has been applied to study the properties of micelles in polymer solutions [11-13]. In this report, a SCFT lattice model is applied [14-16]. In earlier publications, we have used the SCFT lattice model to study the phase behavior of physically associating polymer solutions [5, 17, 18]. It is established that the temperature-dependent behavior of aggregates is affinitive to chain architecture [5], and the effect of polymer concentration is in a way similar to that of chain architecture [18]. Now amphiphilic ABA symmetric triblock copolymer solutions are studied using SCFT lattice model. The focus is made on the effects of the length of hydrophobic end block and polymer concentration on the broadness of the transition observed. It is found that the magnitude of the transition broadness is related to the relative changes of the eductions of nonsticker and solvent from micellar cores.

\section{Theory}

This section briefly describes the self-consistent field theory (SCFT) lattice model for $n_{\mathrm{P}}$ amphiphilic ABA symmetric triblock copolymers which is assumed to be incompressible. Each triblock molecule is composed of $2 N_{\text {st }}$ sticker segments forming two hydrophobic end A block and $N_{\text {ns }}$ nonsticker segments forming the hydrophilic middle B block, distributed over a lattice; the degree of polymerization of the chain is $N\left(=2 N_{\mathrm{st}}+N_{\mathrm{ns}}\right)$ and the total number of lattice sites is $N_{\mathrm{L}}$. In addition to polymer monomers, $n_{\mathrm{h}}$ solvent molecules are placed on the vacant lattice sites. Stickers, nonsticky monomers and solvent molecules have the same size and each occupies one lattice site, and thus $N_{\mathrm{L}}=n_{\mathrm{h}}+n_{\mathrm{P}} N$. Nearest neighbor pairs of stickers have attractive interaction $-\epsilon$ with $\epsilon>0$, which is the only non-bound interaction in the present system. The approximation of the attractive interaction energy [17] is expressed as:

$$
\frac{U}{k_{\mathrm{B}} T}=-\chi \sum_{r} \widehat{\phi}_{\mathrm{st}}(r) \widehat{\phi}_{\mathrm{st}}(r)
$$

where $\chi$ is the Flory-Huggins interaction parameter in the solutions, which equals $\left(z / 2 k_{\mathrm{B}} T\right) \epsilon, z$ is the coordination number of the lattice used, where $\sum_{r}$ means the summation over all the lattice sites $r$ and. $\widehat{\phi}_{\text {st }}(r)=\sum_{j} \sum_{s \in \text { st }} \delta_{r, r_{j, s}}$ is the volume fraction of stickers on the site $r$, where $j$ and $s$ are the indexes of chain and monomer of a polymer, respectively. $s \in$ st means that the $s$ th monomer belongs to the sticker monomer type. In this simulation, we perform the SCFT calculations in the canonical ensemble, and the field-theoretic free energy $F[17,19]$ is defined as

$$
\frac{F\left[\omega_{+}, \omega_{-}\right]}{k_{\mathrm{B}} T}=\sum_{r}\left\{\frac{1}{4 \chi} \omega_{-}^{2}(r)-\omega_{+}(r)\right\}-n_{\mathrm{P}} \ln Q_{\mathrm{P}}\left[\omega_{\mathrm{st}}, \omega_{\mathrm{ns}}\right]-n_{\mathrm{h}} \ln Q_{\mathrm{h}}\left[\omega_{\mathrm{h}}\right]
$$

where $Q_{\mathrm{h}}$ is the partition function of a solvent molecule subject to the field $\omega_{\mathrm{h}}(r)=\omega_{+}(r)$, which is defined as $Q_{\mathrm{h}}=\left(1 / n_{\mathrm{h}}\right) \sum_{r} \exp \left[-\omega_{\mathrm{h}}(r)\right]$. $Q_{\mathrm{P}}$ is the partition function of a noninteraction polymer chain subject to the fields $\omega_{\mathrm{st}}(r)=\omega_{+}(r)-\omega_{-}(r)$ and $\omega_{\mathrm{ns}}(r)=\omega_{+}(r)$, which act on sticker and nonsticker segments, respectively.

Minimizing the free energy function $F$ with $\omega_{-}(r)$ and $\omega_{+}(r)$ leads to the following saddle point equations:

$$
\begin{gathered}
\omega_{-}(r)=2 \chi \phi_{\mathrm{st}}(r), \\
\phi_{\mathrm{st}}(r)+\phi_{\mathrm{ns}}(r)+\phi_{\mathrm{h}}(r)=1,
\end{gathered}
$$

where

$$
\phi_{\mathrm{st}}(r)=\frac{1}{z N_{\mathrm{L}}} \frac{n_{\mathrm{P}}}{Q_{\mathrm{P}}} \sum_{s \in \mathrm{st}} \sum_{\alpha_{s}} \frac{G^{\alpha_{s}}(r, s \mid 1) G^{\alpha_{s}}(r, s \mid N)}{G(r, s)}
$$

and

$$
\phi_{\mathrm{n} s}(r)=\frac{1}{z N_{\mathrm{L}}} \frac{n_{\mathrm{P}}}{Q_{\mathrm{P}}} \sum_{s \in \mathrm{ns}} \sum_{\alpha_{s}} \frac{G^{\alpha_{s}}(r, s \mid 1) G^{\alpha_{s}}(r, s \mid N)}{G(r, s)}
$$


are the average numbers of sticker and nonsticker segments at $r$, respectively, and

$$
\phi_{\mathrm{h}}(r)=\frac{1}{N_{\mathrm{L}}} \frac{n_{\mathrm{h}}}{Q_{\mathrm{h}}} \exp \left[-\omega_{\mathrm{h}}(r)\right]
$$

is the average number of solvent molecules at $r . Q_{\mathrm{P}}$ is expressed as

$$
Q_{\mathrm{P}}=\frac{1}{z N_{\mathrm{L}}} \sum_{r_{N}} \sum_{\alpha_{N}} G^{\alpha_{N}}(r, N \mid 1),
$$

where $r_{N}$ and $\alpha_{N}$ denote the position and orientation of the $N$ th segment of the chain, respectively. $\sum_{r_{N}} \sum_{\alpha_{N}}$ means the summation over all the possible positions and orientations of the $N$ th segment of the chain, respectively. $G^{\alpha_{s}}(r, s \mid 1)$ and $G^{\alpha_{s}}(r, s \mid N)$ are the end segment distribution functions of the $s$ th segment of the chain. $G(r, s)$ is the free segment weighting factor.

Following the scheme of Schentiens and Leermakers [20], $G^{\alpha_{s}}(r, s \mid 1)$ is the end segment distribution function of the sth segment of the chain, which is evaluated from the following recursive relation:

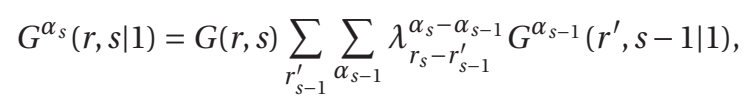

where $G(r, s)$ is the free segment weighting factor and is expressed as

$$
G(r, s)= \begin{cases}\exp \left[-\omega_{\mathrm{ns}}\left(r_{s}\right)\right], & s \in \mathrm{ns}, \\ \exp \left[-\omega_{\mathrm{st}}\left(r_{s}\right)\right], & s \in \mathrm{st} .\end{cases}
$$

The initial condition is $G^{\alpha_{1}}(r, 1 \mid 1)=G(r, 1)$ for all the values of $\alpha_{1}$. In the above expression, the values of $\lambda_{r_{s}-r_{s-1}^{\prime}}^{\alpha_{s-1}}$ depend on the chain model used. We assume that

$$
\lambda_{r_{s}-r_{s-1}^{\prime}}^{\alpha_{s}-\alpha_{s-1}}= \begin{cases}0, & \alpha_{s}=\alpha_{s-1} \\ 1 /(z-1), & \text { otherwise }\end{cases}
$$

Another end segment distribution function $G^{\alpha_{s}}(r, s \mid N)$ is evaluated from the following recursive relation:

$$
G^{\alpha_{s}}(r, s \mid N)=G(r, s) \sum_{r_{s+1}^{\prime}} \sum_{\alpha_{s+1}} \lambda_{r_{s+1}^{\prime}-r_{s}}^{\alpha_{s+1}-\alpha_{s}} G^{\alpha_{s+1}}\left(r^{\prime}, s+1 \mid N\right),
$$

with the initial condition $G^{\alpha_{N}}(r, N \mid N)=G(r, N)$ for all the values of $\alpha_{N}$. In this work, the chain is described as a random walk without the possibility of direct backfolding. Although self-intersections of a chain are not permitted, the excluded volume effect is sufficiently taken into account [21].

The saddle point is calculated using the pseudo-dynamical evolution process [17]. The calculation is initiated from appropriately random-chosen fields $\omega_{+}(r)$ and $\omega_{-}(r)$, and stopped when the change of free energy $F$ between two successive iterations is reduced to the needed precision. The resulting configuration is taken as a saddle point one. By comparing the free energies of the saddle point configurations obtained from different initial fields, the relative stability of the observed morphologies can be assessed.

\section{Result and discussion}

In our studies, the amphiphilic ABA symmetric triblock copolymers depend on three tunable molecular parameters: $\chi$ (the Flory-Huggins interaction parameter), $N_{\mathrm{ns}}$ (the length of hydrophilic middle block, in this paper $N_{\mathrm{ns}}=9$ ) and $N_{\mathrm{st}}$ (the length of each hydrophobic end block). The simulation calculations are performed in a three-dimensional simple cubic lattice with periodic boundary condition. The results presented below are obtained from the lattice with $N_{\mathrm{L}}=26^{3}$. The focus is made on the temperature behavior of micelle morphologies when the length of hydrophobic end block changes.

Figure 1 shows the phase diagram of the systems with different length of each hydrophobic end block $N_{\text {st }}$. When $\chi$ is increased, micelles are observed as a inhomogenous morphology if $N_{\mathrm{st}}=11$. The $\chi$ value on micellar boundary increases with decreasing $\bar{\phi}_{\mathrm{P}}$. When $N_{\mathrm{st}}$ is increased, at fixed $\bar{\phi}_{\mathrm{P}}$, the $\chi$ value on 


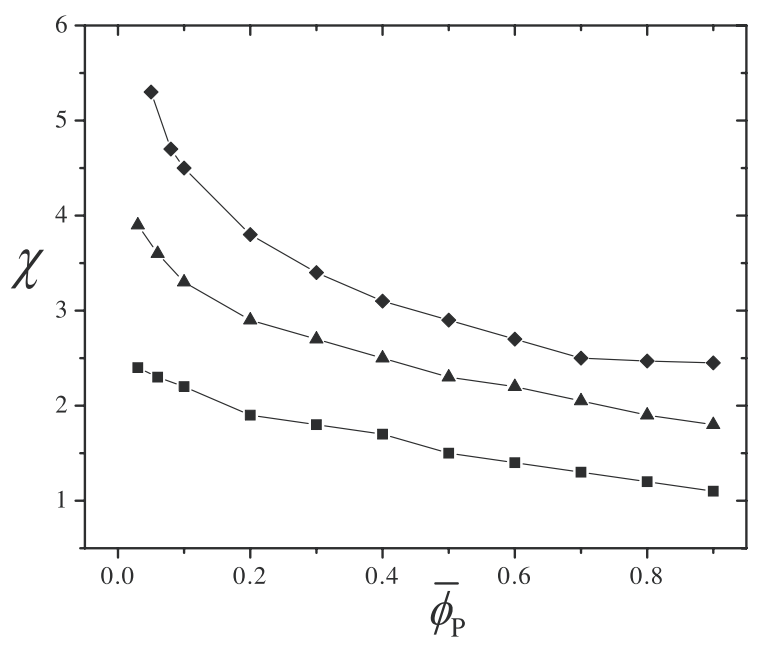

Figure 1. The phase diagram for the systems with different lengths of each hydrophobic end block $N_{\text {st }}$. The boundary between homogenous solutions (blow boundary) and micelle morphology (above boundary) is obtained. The squares, triangles and diamonds correspond to the boundaries for $N_{\mathrm{st}}=4,2,1$, respectively.

micellar boundary shifts to a small value. The increase in the length of hydrophobic end block is favorable to the occurrence of micelles in the system.

The variation of the average number of stickers at the micellar cores denoted by $\bar{\phi}_{\mathrm{st}}^{\mathrm{co}}$ with the $\chi$ deviation from micellar boundary $\chi_{r}$ is calculated. For different $N_{\mathrm{st}}$ at $\bar{\phi}_{\mathrm{P}}=0.8$ and different $\bar{\phi}_{\mathrm{P}}$ at $N_{\mathrm{st}}=4$, the curves of $\bar{\phi}_{\text {st }}^{\text {co }}\left(\chi_{r}\right)$ are shown in figure 2 (a) and (b), respectively. When $N_{\text {st }}=1$, as shown in figure 2)(a), $\bar{\phi}_{\text {st }}^{\text {co }}$ rises and approaches to 1 with an increase in $\chi_{r}$. When $N_{\text {st }}$ is increased, the value of $\bar{\phi}_{\text {st }}^{\text {co }}$ at fixed $\chi_{r}$ decreases, and its temperature-dependent range goes up. For $N_{\mathrm{st}}=4$ [see figure 2](b)], when $\bar{\phi}_{\mathrm{P}}$ is decreased, the value of $\bar{\phi}_{\text {st }}^{\text {co }}$ at fixed $\chi_{r}$ does monotonously increase only in the $\chi_{r}$ range near $\chi_{r}=0$. When $\chi_{r}$ is increased to some extent, at the middle concentration regimes, $\bar{\phi}_{\mathrm{st}}^{\mathrm{co}}$ at fixed $\chi_{r}$ decreases with a decreasing $\bar{\phi}_{\mathrm{P}}$. It is shown that the magnitude of the temperature-dependent range of micelle aggregation does not monotonously change with $\bar{\phi}_{\mathrm{P}}$, which is different from the case of changing $N_{\mathrm{st}}$ at fixed $\bar{\phi}_{\mathrm{P}}$.

\footnotetext{
${ }^{1}$ The structural morphology of MFH morphology [17] occurs at a narrow region of $\Delta \chi=0.1$ neighboring the micellar boundary
} when $\bar{\phi}_{\mathrm{P}}>0.7$ (not shown), which is ignored.
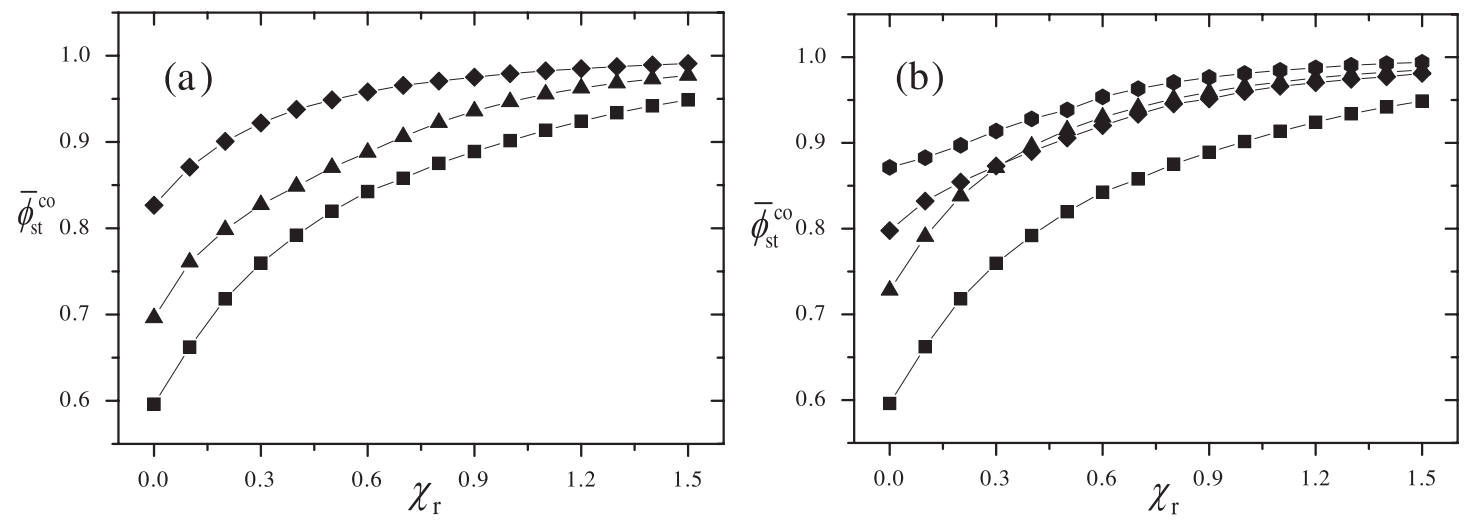

Figure 2. The variations of average numbers of stickers at the micellar cores with the $\chi$ deviation from micellar boundary $\chi_{r}$, for various lengths of each hydrophobic end block $N_{\mathrm{st}}$ at $\bar{\phi}_{\mathrm{P}}=0.8$ and different $\bar{\phi}_{\mathrm{P}}$ at $N_{\mathrm{st}}=4$, are presented by figure 2(a) and (b), respectively. In figure (a), The squares, triangles and diamonds correspond to $N_{\mathrm{st}}=4,2,1$, respectively; In figure (b), the squares, triangles, diamonds and hexagons denote $\bar{\phi}_{\mathrm{P}}=0.8,0.4,0.2,0.1$, respectively. 

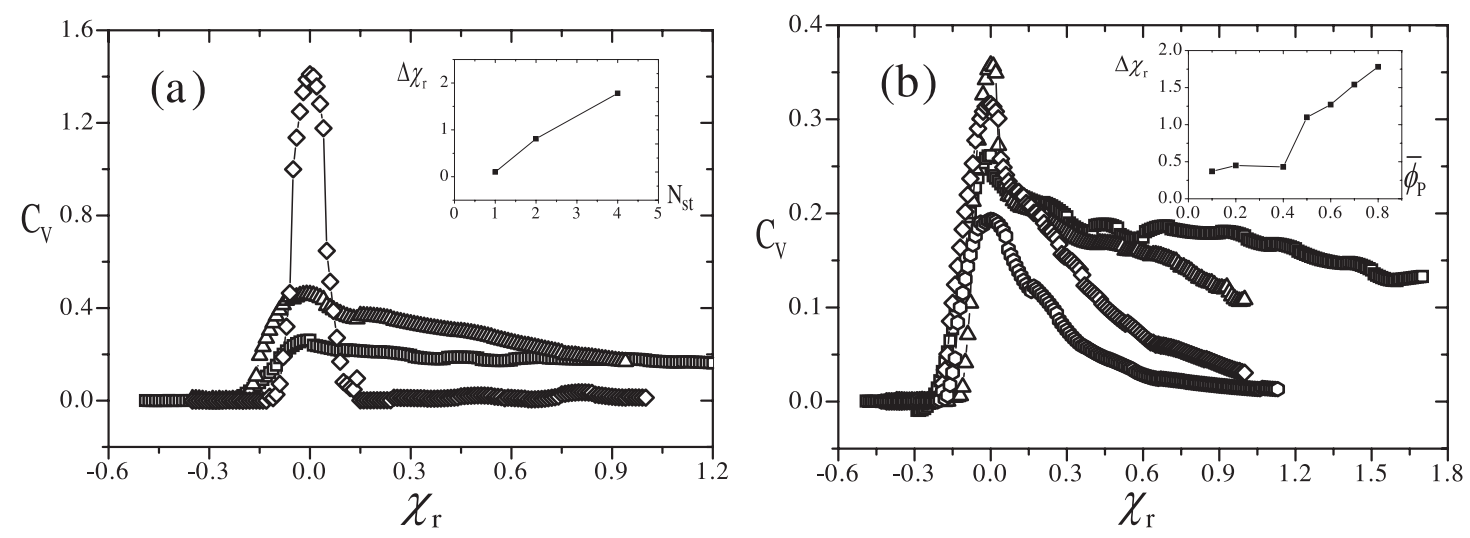

Figure 3. The changes of specific heat capacity in different amphiphilic ABA symmetric triblock copolymers with the $\chi$ deviation from micellar boundary $\chi_{r}$ are presented by figure 3 (a) and (b) corresponding to the systems shown by figure 2(a) and (b), respectively.

The half-width of a specific heat peak may be an intrinsic measure of transition broadness. [5, 22]. In this work, the heat capacity per site of amphiphilic ABA symmetric triblock copolymers is expressed as (in the unit of $k_{\mathrm{B}}$ ):

$$
C_{V}=\left(\frac{\partial U}{\partial T}\right)_{N_{\mathrm{L}}, n_{\mathrm{P}}}=\frac{1}{N_{\mathrm{L}}} \chi^{2} \frac{\partial}{\partial \chi}\left[\sum_{r} \phi_{\mathrm{st}}^{2}(r)\right] .
$$

For various $N_{\mathrm{st}}$ at $\bar{\phi}_{\mathrm{P}}=0.8$ and different concentrations at $N_{\mathrm{st}}=4$, the $C_{V}\left(\chi_{r}\right)$ curves of the unimermicelle transition are shown in figure 3 (a) and 3 (b), respectively. For unimer-micelle transition, a peak appears in each $C_{V}\left(\chi_{r}\right)$ curve. When $N_{\text {st }}$ is increased, as shown in figure 3 (a), the half-width of the transition peak rises, and the symmetry and the height of the transition peak decrease. The broadness of unimer-micelle transition increases with increasing the length of hydrophobic end block, which is in reasonable agreement with that on temperature-dependent range of micellar aggregation. Whereas for the case of changing $\bar{\phi}_{\mathrm{P}}$ at $N_{\mathrm{st}}=4$, the half-width and height of the transition peak do not monotonously change with $\bar{\phi}_{\mathrm{P}}$. When $\bar{\phi}_{\mathrm{P}}$ is decreased, the symmetry of the peak always increases, the height of the transition peak firstly increases, and then decreases. Its half-width initially drops, and then nearly remains constant with a decreasing $\bar{\phi}_{\mathrm{P}}$. In other words, at high concentrations the broadness of unimer-micelle transition is affected by polymer concentration. In middle and low concentration regimes, the height of the transition peak is affected by the change of polymer concentration. However, the transition broadness is almost unrelated to polymer concentration. It is shown that the effect of polymer concentration on the transition broadness is consistent with that on the temperature-dependent range of micellar aggregation.

It is obvious that the increase in the degree of aggregation at micellar cores results from the eductions of nonsticky monomers and solvents. Micelles appear when temperature drops below the critical micelle temperature. With a further decrease of temperature, solvents and nonstickers continue to be expelled from micellar cores, and the degree of aggregation of micellar cores strengthens. Therefore, the temperature-dependent behavior of micellar aggregation brings about the existence of the transition broadness, rather than a transition point. The broadness of unimer-micelle transition increases with increasing the length of hydrophobic end block (i.e., the length of chain), which is consistent with the effect of decreasing the length of hydrophilic middle block between neighboring hydrophobic blocks, at a fixed chain length, in associative polymer solutions [5]. It is demonstrated that the broadness of the transitions concerned with micelles is determined by the ratio of hydrophobic to hydrophilic blocks, which is not related to the length of polymer chain.

Furthermore, the relative magnitude of contributions of nonsticky monomers and solvents to aggregation of micellar cores should be related to micelle structure and the relationship among micelles. At high concentrations, when the length of hydrophobic end block $N_{\text {st }}$ is increased, the micellar volume fraction in the system rises and the micelle structure tends to be intricate. These factors result in the difficulties of the eductions of nonsticky monomers and solvents from micellar cores. Therefore, with an 

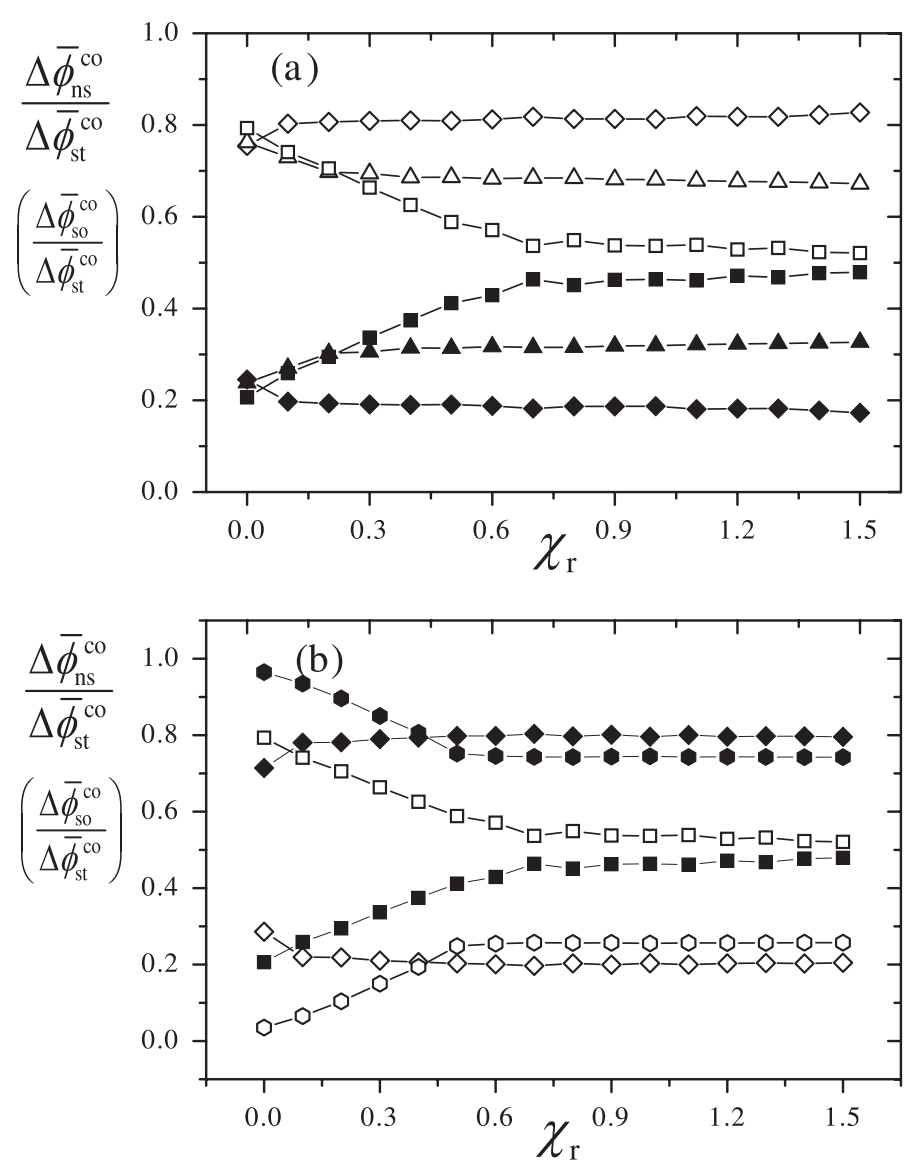

Figure 4. The variation of the ratios of the changes of average numbers of nonstickers and solvents to that of stickers at the micellar cores when the $\chi$ deviation from micellar boundary $\chi_{r}$, for various lengths of each hydrophobic end block $N_{\mathrm{st}}$ at $\bar{\phi}_{\mathrm{P}}=0.8$ and different $\bar{\phi}_{\mathrm{P}}$ at $N_{\mathrm{st}}=4$, is presented by figure 4 (a) and (b), respectively. The change $\Delta \phi_{s}^{\mathrm{co}}\left(\chi_{r}\right)$ equals $\phi_{s}^{\mathrm{co}}\left(\chi_{r}\right)-\phi_{s}^{\mathrm{co}}\left(\chi_{r}-0.1\right)$, where $s$ denotes st, ns, so, respectively. In figure (a), The open and solid squares, triangles and diamonds correspond to the cases for $N_{\mathrm{st}}=4,2,1$, respectively; In figure (b), the open and solid squares, diamonds and hexagons denote the cases for $\bar{\phi}_{\mathrm{P}}=0.8,0.4,0.1$, respectively.

increase in $N_{\mathrm{st}}$ at fixed $\bar{\phi}_{\mathrm{P}}$, the temperature-dependent range of aggregation of micellar cores, as well as the transition broadness, rises. Moreover, when $N_{\text {st }}$ is relatively big, the relationship among micelles is strong, which markedly hampers the eduction of nostickers, thus the contribution of solvents will be rather important. As shown in figure 4 (a), when $N_{\text {st }}$ is increased from $N_{\text {st }}=1$, given a fixed $\bar{\phi}_{\mathrm{P}}$, the contribution of nonstickers to aggregation of stickers goes down and that of solvents rises with an increasing $\chi_{r}$, at the neighborhood of $\chi_{r}>0$. It is noted that the evidently temperature-dependent range of the ratios of the changes of average numbers of nonstickers and solvents to that of stickers at the micellar cores rises with an increasing $N_{\text {st }}$. The larger is the evidently temperature-dependent range of the above ratio, the bigger is the transition broadness. It is shown that the magnitude of the transition broadness is concerned with the changes of the relative magnitudes of the eductions of nonstickers and solvents from micellar cores.

In high concentrations, when polymer concentration is decreased, for a large $N_{\mathrm{st}}$, the effect of the relationship among micelles on eductions of nonstickers and solvents evidently dies down. Therefore, the transition broadness decreases with a decreasing $\bar{\phi}_{\mathrm{P}}$. At intermediate and low concentrations, the effect of the relationship among micelles on eductions of nonstickers and solvents is weak, especially to nonstickers. Seen from figure 4(b), with an increasing $\chi_{r}$ from $\chi_{r}=0.1$, the ratios of the changes of average numbers of nonstickers and solvents to that of stickers at the micellar cores nearly remain 
constant, where solvents and nonstickers are expelled proportionally. When polymer concentration is decreased to some extent, the aggregation of micellar cores is dominated by the eductions of solvents. Due to the existence of a large quantity of solvents among micellar cores, it is difficult to expel a small amount of solvent at the micellar core. Therefore, although the effect of the relationship among micelles is already very weak, the transition broadness always remains constant with a decrease in $\bar{\phi}_{\mathrm{P}}$ when the contribution of nonstickers is rather important and is temperature-dependent in a larger range of $\chi_{r}$ [figure 4(b)].

\section{Conclusion and summary}

The effects of the length of each hydrophobic end block $N_{\text {st }}$ and polymer concentration $\bar{\phi}_{\mathrm{P}}$ on the transition broadness in amphiphilic ABA symmetric triblock copolymer solutions are studied using the self-consistent field lattice model. When $N_{\text {st }}$ is changed, at fixed $\bar{\phi}_{\mathrm{P}}$, micelles occur at a higher temperature, and the broadness of unimer-micelle transition also increases. Compared with associating polymer solutions, it is found that the magnitude of the transition broadness is determined by the ratio of hydrophobic to hydrophilic blocks rather than by the length of polymer chain. When $\bar{\phi}_{\mathrm{P}}$ is decreased, given a large $N_{\text {st }}$, the transition does not change monotonously. In high concentration regimes, the transition broadness decreases with decreasing $\bar{\phi}_{\mathrm{P}}$, and in intermediate and low concentration regimes, the transition broadness remains constant with $\bar{\phi}_{\mathrm{P}}$. It is demonstrated that the magnitude of the transition broadness is concerned with the changes of the relative magnitudes of the eductions of nonstickers and solvents from micellar cores.

\section{Acknowledgements}

This research is financially supported by the National Nature Science Foundations of China (11147132) and the Inner Mongolia municipality (2012MS0112), and the Innovative Foundation of Inner Mongolia University of Science and Technology (2011NCL018).

\section{References}

1. Kataoka K., Harada A., Nagasaki Y., Adv. Drug Delivery Rev., 2001, 47, 113; doi 10.1016/S0169-409X(00)00124-1

2. Riess G., Prog. Polym. Sci., 2003, 28, 1107; doi 10.1016/S0079-6700(03)00015-7

3. Bhatia S.R., Mourchid A., Joanicot M., Curr. Opin. Colloid Interface Sci., 2001, 6, 471; doi 10.1016/S1359-0294(01)00122-4

4. Fatimi A., Tassin J.F., Quillard S. , Axelos M.A.V., Weiss P., Biomaterials, 2008, 29, 533; doi 10.1016/j.biomaterials.2007.10.032.

5. Han X.G., Zhang X.F., Ma Y.H., Condens. Matter Phys., 2012, 15, No. 3, 33602; doi 10.5488/CMP.15.33602.

6. Goldmints I., Gottberg F.K.V., Smith K.A., Hatton T.A., Langmuir, 1997, 13, 3659; doi 10.1021/la970140v

7. Orland H., Schick M., Macromolecules, 1996, 29, No. 2, 713; doi 10.1021/ma9508461

8. Matsen M.W., Schick M., Phys. Rev. Lett., 1994, 72, No. 16, 2660; doi 10.1103/PhysRevLett.72.2660

9. Tang P., Qiu F., Zhang H.D., Yang Y.L., Phys. Rev. E, 2004, 69, No. 3, 031803.

10. He X., Liang H., Huang L., Pan C., J. Phys. Chem. B, 2004, 108, No. 5, 1731; doi 10.1021/jp0359337.

11. Cavallo A., Muller M., Binder K., Macromolecules, 2006, 39, No. 26, 9539; doi 10.1021/ma061493g

12. Jelinek K., Limpouchova Z., Uhlk F., Prochazka K., Macromolecules, 2007, 40, No. 21, 7656; doi $10.1021 / \mathrm{ma} 070928 \mathrm{c}$

13. Charlaganov M., Borisov O.V., Leermakers F.A.M., Macromolecules, 2008, 41, 3668; doi 10.1021/ma800130q

14. Chen J.Z., Zhang C.X., Sun Z.Y., Zheng Y.S., An L.J., J. Chem. Phys., 2006, 124, 104907; doi 10.1063/1.2176619

15. Chen J.Z., Sun Z.Y., Zhang C.X., An L.J., Tong Z., J. Chem. Phys., 2007, 127, 024105; doi 10.1063/1.2750337

16. Chen J.Z., Sun Z.Y., Zhang C.X., An L.J., Tong Z., J. Chem. Phys., 2008, 128, 074904; doi 10.1063/1.2831802

17. Han X.G., Zhang C.X., J. Chem. Phys., 2010, 132, 164905; doi 10.1063/1.3400648

18. Han X.G., Zhang X.F., Ma Y.H., Zhang C.X., Guan Y.B., Condens. Matter Phys., 2011, 14, No. 4, 43601; doi $10.5488 / C M P .14 .43601$

19. Fredrickson G.H., The Equilibrium Theory of Inhomogenous Polymers, Clarendon Press, Oxford, 2005. 
20. Leermakers F.A.M., Scheutjens J.M.H.M., J. Chem. Phys., 1988, 89, No. 5, 3264; doi 10.1063/1.454931

21. Medvedevskikh Y.G., Condens. Matter Phys., 2001, 4, No. 2, 209; doi 10.5488/CMP.4.2.209

22. Douglas J.F., Dudowicz J., Freeda K.F., J. Chem. Phys., 2006, 125, 114907; doi 10.1063/1.2356863.

\title{
Вплив концентрації полімера і довжини гідрофобного прикінцевого блоку на ширину переходу мономер-міцела в АВА симетричних триблочних амфіфільних кополімерних розчинах
}

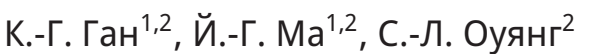 \\ 1 Школа математики, фізики і біологічної інженерії, університет науки і технологій внутрішньої Монголії, \\ Баоту 014010, Китай \\ 2 Головна лабораторія інтегрованого використання мультиметалічних ресурсів Баян Обо, університет \\ науки і технології внутрішньої Монголії, Баоту 014010, Китай
}

\begin{abstract}
Вплив довжини кожного гідрофобного прикінцевого блоку $N_{\text {st }}$ і концентрації полімера $\bar{\phi}_{\mathrm{P}}$ на ширину переходу в симетричних АВА триблочних амфіфільних кополімерних розчинах досліджується шляхом використання ґраткової моделі самоузгодженого поля. Коли система охолоджена, спостерігаються міцели, тобто відбувається перехід однорідний розчин (мономер)-міцела. Якщо $N_{\text {st }}$ зростає при сталому $\bar{\phi}_{\mathrm{P}}$, то міцели виникають при високій температурі, а температурно залежна область агрегації міцел і півширина піку питомої теплоємності для переходу мономер-міцела зростають монотонно. Порівнюючи 3 асоціативними полімерами, знайдено, що величина ширини переходу визначається відношенням гідрофобних блоків до гідрофільних, а не довжиною ланцюга. Коли $\bar{\phi}_{\mathrm{P}}$ зменшується при великому значенні $N_{\mathrm{st}}$, температурно залежна область міцелярної агрегації та півширина піку питомої теплоємності спочатку зменшуються, а потім залишаються майже сталими. Показано, що ширина переходу пов'язана зі зміною відносних величин виділення незв'язувальної речовини і розчинників з міцелярних корів.
\end{abstract}

Ключові слова: ширина переходу, самоузгоджене поле, амфіфільний кополімер 